\title{
Crisis communication strategies of police organizations subsequent negative public perception and media framing
}

\author{
Alexia L. Knox \\ Marquette University \\ Diederich College of Communication \\ 1131 West Wisconsin Avenue, Wisconsin, Milwaukee USA
}

\begin{abstract}
This research task examines crisis communication strategies of police organizations acting as spokespersons, subsequent negative public perceptions of police organizations, while attempting to understand how external and some internal variables, particularly, human processes of emotions and behaviors of police officers, victims of violence and minority groups, might contribute to negative crisis outcomes, as described in the regenerative crisis model, as the crisis becomes more prevalent and persuasive through media framing.
\end{abstract}

Keywords - Police communications, human emotion processes, regenerative crisis model, minorities, victims of violence

SUGGESTED CITATION: Knox, A. L. (2020). Crisis communication strategies of police organizations subsequent negative public perception and media framing. Proceedings of the International Crisis and Risk Communication Conference, Volume 3 (pp. 21-24). Orlando FL: Nicholson School of Communication and Media. https://www.doi.org/10.30658/icrcc.2020.5

\section{INTRODUCTION}

The use of crisis communications has become increasingly valuable for various organization types. This research task will examine crisis management strategies of police organizations: environmental scanning, message tailoring, applicable communication theories, specfically, the situational crisis communication theory and attribution of responsibility, to understand negative public perceptions of police organizations while examining how external variables, categorically, the perceptions of victims of violence and minorities as stakeholders, can influence crisis communications of police organizations. Although police organizations are public servants, during crises they may act as spokespersons and take on the role of media while framing crises and shaping public perception despite the organizations' connection to negative processes and societal crises. As a result, subsequent advanced environmental scanning of both internal and external variables within the environment, such as emotions, attitudes and opinions or processes of police officers, minorities and victims of violence, for example, might contribute to an analysis of police communications due tue its tailored messaging to the public from the police organizations, which are adaptable and changeable to groups. Furthermore, a police organization is an organization possessing implicit authority to protect and serve publics, police organizations also have a historically cataclysmic reputation regarding interactions with minorities and victims of violence can impact the credibility of their message when acting as spokespersons.

The complexities of police communications and the impact of stakeholder emotions, attitudes and opinions about police organizations can influence the persuasiveness, reputation, credibility of police communications and organizations, and the management of the crisis, presumptively, when messaging is overshadowed by preceding crises of police organiations and negative public perceptions held by stakeholders. As a result, the regeneration of another crisis during a crisis could transpire due to lack of credibility of the police organization amongst publics, which will be discussed in this research task. The literature review will examine applicable crisis communication theories and crisis management strategies to better understand police communications and the effects of public perception. 


\section{LITERATURE REVIEW}

\section{CRISIS COMMUNICATION \& SITUATIONAL CRISIS COMMUNICATION THEORY (SCCT)}

Organizations experience crises and crisis communications is a deliberate action of an organization subsequent an event. Depending on the perceptions of publics or stakeholders, an event may or may not be considered a crisis. Additionally, not all publics perceive any event as a crisis. Situational crisis communication theory (SCCT) focuses on how individuals perceive and react to a crisis, for instance, considering a person's behavioral intentions to a crisis. SCCT asserts that situations that relate to victim, accidental, or preventable attributions, will determine the crisis response based on stakeholder perceptions. Further, stakeholder perception about a situation or crisis is important because the selection of crisis communications is based on the perceptions of stakeholders. Research has suggested that responses to organizational crises can change how crises are perceived. Police organizations can develop crisis communications to influence the perception of crisis responsibility as perceived by stakeholders but due to police organizations' having been involved in preceding societal crises, it is expected for the public to attribute blame for a subsequent crisis onto the police organization when the organization is acting as a spokesperson during a crisis adding further threat to its reputation and credibility or regenerate further crises.

\section{HUMAN PROCESSES OF EMOTIONS IN CRISIS COMMUNICATIONS}

The public conceptualizes crisis through emotion; and emotions can influence perception. The default emotional response to a crisis is anxiety [1]. Emotions are directly linked to the public attributing responsibility to an organization in crisis situations. Connecting emotions to a crisis type and attributing responsibility to an organization is a very complex psychological process. According to Coombs and Holladay [2], “....anger increases with attributions of crisis responsibility..." Stakeholder feelings of anger or sympathy is considered in crisis communications because stakeholders' perceptions are valuable when attributing responsibility and developing crisis communications. These stakeholder groups share experiences involving police contact and suggestively demonstrate similar public perceptions about police organizations. Emotional processes are also experienced by police organizations. Both the expression and suppression of anger occur frequently in police work [3]. Also, practicing higher emotional control may eventually reduce a police officer's vulnerability to be sensitive toward others. This display of anger, lack of emotion or toughness reduces a police organization's credibility and persuasiveness amongst some publics which will diminish the message and create emotionally anxious and angry publics when police organizations act as spokespersons during crises. Although, law enforcement is a stressful profession and the emotional climate of the profession can result in anger on the job [3], anger can affect police communications directed to publics. It is possible that police officers can individually experience emotions of anger which might attribute crisis responsibility when a crisis involving police organizations is perceived as preventable.

\section{PUBLIC PERCEPTIONS \& MEDIA FRAMING OF POLICE ORGANIZATIONS}

Police organizations using spokespersons to deliver messages to the public aids in shaping and framing the perceptions of the public. A spokesperson can maintain consistency of the message and act as a trusted voice which the public can rely. The police organization is presented as a trusted voice, but the notion of a police organization being a trusted voice becomes problematic when certain publics feel emotions of anger or anxiety due to preceding crises involving police organizations made prevalent through the media. Influencing public perception can be demonstrated through media framing. Police Executive Research Forum [4], “... high-profile incidents, including many involving the use of lethal force... have resulted in what some have referred to as the 'post-Ferguson effect,' in which members of the public lose trust in the police. Negative news stories about policing may be creating new challenges." Further, research by [5] showed that the main determining factors influencing perceptions of police organizations were based on their denial of responsibility and on their denial of the victim." Notwithstanding these considerations, police communications that negatively influence public perceptions may not be necessarily intentional, but perhaps a lapse in training. According to Police Executive Research Forum (2010), “...officers receive considerably less training on subjects such as deescalation, crisis intervention, tactical communications..." Subsequent Ferguson and other incidents involving police violence, publics may not perceive the police organization or their message as credible. On the contrary, police officers may believe that publics may not trust or value their role as police officers.

\section{METHODS}

The following tools were used to investigate and analyze related data in order to develop approaches and hypothetical responses to research questions:

1. Case Study about police organization regarding internal police communication issues [6]. (Interview of police officers based on Explanatory Interview Guide, Survey based on International Cultural Audit Survey (ICA) and Questionnaire based on Wilcoxon signed rank test.)

2. Survey about domestic violence victims' perception of law enforcement responses [7]. 
3. Survey of minority victims of violence showing a census of all deaths that occur during the process of arrest or during an attempt to obtain custody by a state or local law enforcement agency (LEA) [8].

4. Survey of officer-involved shootings of minorities that resulted in death based on causal-comparative quantitative data [9].

\section{PROCEDURES}

There were 41 participants who were police officers or a $20 \%$ quota sample. Sixty-eight percent of the police officers audited were in senior police officer or superintendent positions and practiced paramilitary styles of communication. The interviews were carried out in police stations and lasted 35-45 minutes. The interview collected qualitative and quantitative data on the perceptions of police officers using a 5-point Likert Scale producing mean scores. Questionnaires tested six cultural dimensions: Teamwork, Morale, Information flow, Involvement, Supervision and Meetings collecting standard qualitative data deriving from mostly close-ended questions. Survey: National Domestic Violence Hotline [7] conducted a survey about law enforcement responses to partner abuse with survivors who used the hotline's chat services. Overall, 637 women with experiences of partner abuse agreed to participate in the survey. Participants were an average of 30 years old, female and white. Police organizations can and have used force when responding to calls. Survey: The Bureau of Justice Statistics, U.S. Department of Justice Office of Justice Programs, performed a collection of data found in the Arrest-Related Deaths (ARD) Program: Pilot Study of Redesigned Survey Methodology Technical Report, data shows a census of all deaths that occur during the process of arrest or during an attempt to obtain custody by a state or local law enforcement agency (LEA) in the United States from June through August 2015[8]. Survey: Washington Post maintains an online database of officer-involved shootings of minorities that resulted in death.

\section{RESULTS}

Results of the case study revealed a critical incident due to limited responses to interviews. Only $25 \%$ of respondents fully participated likely due to the militant style of communications of a police organization. This number consisted of nearly sixty-eight percent of the organizational staff, who were senior officers. The interview results determined that junior police officers felt they could share information with their immediate managers and share new ideas, the majority of officers perceived communication with senior management was positive; and over one-third of respondents raised the problem of communications with other departments. I expected junior officers to have mostly ineffective relationships with management but according to the ICA questionnaire results, respondents were able to share new ideas with management, have an approachable supervisor, receive criticism in a positive manner and a 'more communication for management' theme scored the highest in another questionnaire that consisted of 105 suggestions for improving communication. The highest mean total of the ICA questionnaire was related to Supervision (3.3) and Teamwork (3.6). The lowest mean total of the ICA questionnaire was related to Involvement (2.1) and Information Flow (2.2).

\section{SURVEYS OF VICTIMS OF VIOLENCE AND MINORITIES}

According to National Domestic Violence Hotline (2015), victims of domestic violence have witnessed police organizations use force and have been fearful of police responses. Four out of five (80\%) of those who had not previously called the police were somewhat or extremely afraid to call them in the future. One in four reported that they would not call the police in the future and seventy percent of women who were victims of domestic violence said that they were afraid calling the police would make things worse (National Domestic Violence Hotline, 2015). According to Washington post, over 300 minorities have been shot and killed by police. The use of force against victims of violence and minorities applied by police organizations in various scenarios has been made prevalent through media framing [9].

\section{DISCUSSION}

The following are hypothetical responses to two research questions listed below for the purposes of discussion:

RQ1: How does public perception of police organizations, based on media framing, particularly, perceptions of victims of violence, including minorities, affect police communications?

H1: Many victims of violence and minorities have had police-contact and media framing can contribute to negative perceptions of police organizations. The narrative consisting of reports of arrest-related deaths, police rapes, domestic violence and police-involved shootings involving minorities and victims of violence, which are shared with publics via media framing, emphasizes subjective narratives of police organizations being involved in societal crises. Such reporting or misreporting of facts via media influences public perception of police organizations amongst any stakeholder, and would impact the deliverability and credibility of police communications. 
RQ2: Is there a relationship between internal police communications and ineffective police communications addressed to the public?

H2: Police officers that do not hold the roles of senior officers or superintendents, such as junior officers, may be conditioned to rely on supervisors for guidance. Based on the data, the communication structure of police organizations consisting of limited interaction between senior officers and junior officers, demonstrate a gap in communication between police officers and senior officers and and need for junior officers to gain acceptance from senior officers which can negatively influence communications towards publics, as a result. According to Stinchcomb [10], the effects of poor communication have been noted to be a cause of stress within police service. It can be presumed that due to police officers' inability to foster communication with senior staff, fulfilling a relationship with other police officers would be secondary. This behavior aligns with the teamwork theme that proposes that the team is selected by default. Police officers are isolated from senior police officers, which may cause stress, isolation, rejection, and emotion suppression on the job that may result in impaired police communications or a lack of police communications. As a result, limited and ineffective police communications towards publics are developed and could translate into use of force instead of communication causing arrest-related deaths, particularly homicides by a police officer.

\section{CONCLUSION}

Data demonstrated that most of the reports related to police involved arrests that resulted in death, particularly, homicide, were framed by the media and not the agency (law enforcement agency). The agency or police organization did not report homicides involving police, which could be perceived by the public as police organizations avoiding accountability or responsibility; allowing the public to establish attribution at the onset of the crisis, creating another crisis based on public perceptions of the police organization created by media framing of the crisis. As a result, publics are emotionally and behaviorally anxious and angry. Police organizations acting as spokespersons should demonstrate transparency in police communications; sharing information with publics and involving publics in environmental scanning to limit tailored messaging to promote trust between police organizations and publics. Police organizations can hold press conferences as spokespersons accepting some responsibility to crises contemporaneously adding credibility to the police organization and to subsequent messaging during pre-crisis, crisis and post-crisis stages.

\section{Author Biography}

Knox, A.L. Master of Arts in Corporate Communications from Marquette University, Milwaukee Wisconsin. U.S. Census Bureau. Alexia.Knox@marquette.edu; Alexia@lexincommunications.com

\section{REFERENCES}

[1] Pang, A., Jung, Hyo-Jung, K, \& Chaideroon, S. (2012). Dealing with emotions of stakeholders during crises: Why should leaders care? https://doi.org/10.4337/9781781006405.00015

[2] Coombs, T. \& Holladay (2010). Handbook of crisis communications. The Handbook of Crisis Communication. United Kingdom: Wiley.

[3] Daus, C. \& Brown, S. (2012, June) The emotional work of police: Research on Emotion in Organizations, 8, 305-328. https://doi.org/10.1108/S1746-9791(2012)0000008016

[4] Author Unknown. (2016). Critical issues in policing series ICAT - integrating communications, assessment, and tactics a training guide for defusing critical incidents. Police Executive Research Forum.

[5] Quarles, D. (2015). Perceptions of police conduct: Media coverage of the Ferguson conflict.

[6] Hargie, O. \& Tourish, D. (2009). Auditing organizational communication: A handbook of research, theory and practice. London: Routledge.

[7] Logan, T. \& Valente, R. (2015). Who will help me? Domestic violence survivors speak out about law enforcement responses. National Domestic Violence Hotline.

[8] Author Unknown, (2019). Arrest-related deaths program: Pilot study of redesigned survey methodology. U.S. Department of Justice Office of Justice Programs Bureau of Justice Statistics TECHNICAL REPORT. NCJ 252675.

[9] Author Unknown (2019). Fatal force. Washington Post.

[10] Stinchcomb, J. (2004). Searching for stress in all the wrong places: Combating chronic organizational stressors in policing, Policy Practice and Research, 5. 259-277. https://doi.org/10.1080/156142604200227594 